\title{
Sustainable Community Development through Homestay Programme
}

\author{
A.M. Dayang Affizah (Corresponding author) \\ Faculty of Economics and Business \\ Universiti Malaysia Sarawak, Malaysia \\ Email: afizah987@yahoo.com
}

Melissa W.

Faculty of Economics and Business

Universiti Malaysia Sarawak, Malaysia

Muhammad Ashraf R.

Faculty of Economics and Business

Universiti Malaysia Sarawak, Malaysia

Received: February 22, 2017 Accepted: March 15, 2017 Published: April 05, 2017

doi:10.5296/jpag.v7i1.11041 URL: http://dx.doi.org/10.5296/jpag.v7i1. 11041

\begin{abstract}
This study analyses the dimensionality of tourist perceived value in community-based homestay tourism context. A survey of 150 visitors to homestay in Kuching, Sarawak was conducted and used to examine the perceived value dimensions in tourism context, statistical analysis and structural equation model were used to verify the validity and reliability of scales used. Satisfaction Level was measured using tested perceived value with six dimensions that illustrated through structural construct, (i) emotional value, (ii) experiential value (host-guest interaction), (iii) experiential value (activity, culture and knowledge), (iv) functional value (establishment), (v) functional value (price), and (vi) functional value (service). The finding shows that emotional, experiential and functional are important determinants of perceived value which affect the visitor's satisfaction level on homestay tourism. Moreover, statistical findings indicated that only five dimensional have positive affect towards Satisfaction Level while function value (establishment) computed a negative
\end{abstract}


affect towards satisfaction.

Keywords: Homestay tourism, Tourist perceived value, Experiential value, Emotional value, Satisfaction level, Exploratory factor approach, Confirmatory factor approach

\section{Introduction}

In Malaysia, eco-tourism development is mainly private-sector led which encouraged to develop and promote eco-tourism destinations in the country (Daud, 2012). Developing eco-lodges, organizing tours and marketing products are led by private sector such as The Malaysia World Wide Fund for Nature (WWF) and Malaysia Nature Society (MNS) that helps to promote eco-tourism activities. In addition, Tourism Industry is the second largest contributor for the economy after manufacturing sector in Malaysia (Abd Aziz, Md Tap and Mahmud, 2013). In the year of 1996, the government of Malaysia accepted national eco-tourism plan that created in 1992 where Malaysian Tourism Policy formulated and identifies eco-tourism as one form of tourism to be expanded and sustained. Furthermore, national eco-tourism plan was intended to serve as an appropriate instrument for sustainable development of Malaysia and it also used as an effective tool for preserve the natural and cultural heritage of the country (Daud, 2012). The idea of homestay is designated to immerse travelers into local culture in the most authentic way. According Ministry of Tourism, the definition of homestay is the place where tourists stay with the host family in both direct and indirect manner. Moreover, homestay is a suggestion for better accommodations which serves potential economic activity in tourism sector (Bhuiyan, Siwar, Ismail and Islam, 2011). Malaysia homestay program allows their cheerful visitors to participate in the hosts daily activities where the learning and communication process can be seen as what stated Kayat (2009), it is an important strength for the homestay program because no other tourism product in Malaysia offers a similar experience of Malaysian rural societies as that offered by the homestay program. Homestay program has gained its momentum in the tourism industry and emerged as an iconic rural tourism activity, even the government of Malaysia also identified Community Based Tourism as a catalyst for rural community development by promoting such program that originally organized by rural societies. The development homestay program in Malaysia was expanding as what have been stated in $9^{\text {th }}$ Malaysia Plan (2006-2010) with main objective where this program will generate income to rural people and willingly to promote the beauty of Malaysia as a best tourist destination by highlighting the amazing various culture of Malaysia. Sarawak is located at the Borneo Island along with Sabah, Brunei and Kalimantan Indonesia. The year of 2013, there are approximately more than 4 million of visitors as stated by Lim (2013). Moreover, the tourism sector has generated revenues from year 2010 to 2012 which is RM8.573 billion and this amount is from both foreign and domestic visitors plus it shows that foreign visitors are more inclined to visit Sarawak rather than domestic visitor for tourism purpose.

Generally, homestay program is practiced in remote and rural areas to promote conservation of nature such as forests, parks, heritage sites and views (Lama, 2013). Furthermore, Sarawak is famous known for its exotic culture backgrounds it's several of indigenous groups such as 


\section{Macrothink}

Melanau, Iban, Bidayuh, orang-ulu and also eye-relaxing astounding nature. From the year of 2009, the number of homestay in Sarawak has been increasing up to 28 in 2011. The growing number of homestays indicates that this tourism is gradually gaining its presence in eco-tourism industry plus benefits for the villagers. Nowadays, homestay has been organized as one way to provide cheap budget accommodation to tourist and the best way to get closer to nature and tradition of a particular ethnic culture (Pusiran and Xiao, 2013). It is good to have increasing number of homestay to promoting the popularity of Sarawak, but this program is difficult to sustain even though it easy to have some enjoyable kick start because it is not commercially viable. There is some numerous challenges in this business environment where it could affects the effectiveness of the program as a whole. This challenge is come from both external and internal factors where from external challenge, it also included such as high competition from neighboring countries and uncertainties in the hospitality industry life cycle (Tourism Malaysia, 2007). However, from internal challenge are identifies to be related to the homestay program (Razalli, 2008) such as low level of service quality and decreasing average occupancy rate which contribute to homestay poor performance. Besides that, there is lack in marketing knowledge by homestay proprietors which deter for a successful business. In addition, this might leads to limited effective information available for further development of homestay program in Sarawak and also affects the credibility of the business in the future. As this program has facing current problems, this study will seeks to determine on the important attributes that affect visitor overall satisfaction in order to enhance the offerings attractive offered by homestay in Kuching, Sarawak in the future.

\section{Theoretical Framework}

There is further perspective of relevance by the study of Song, Li, Van Der Veen and Chen (2011) which focusing on the sectorial level satisfaction. Figure 1 will illustrates the structural equation model which tourists' satisfaction is evaluated with relevant preceding circumstances and its effects in the sectorial-level of tourist satisfaction. 
Figure 1: Hypothesized Sectoral-Level Tourist Satisfaction Index Model

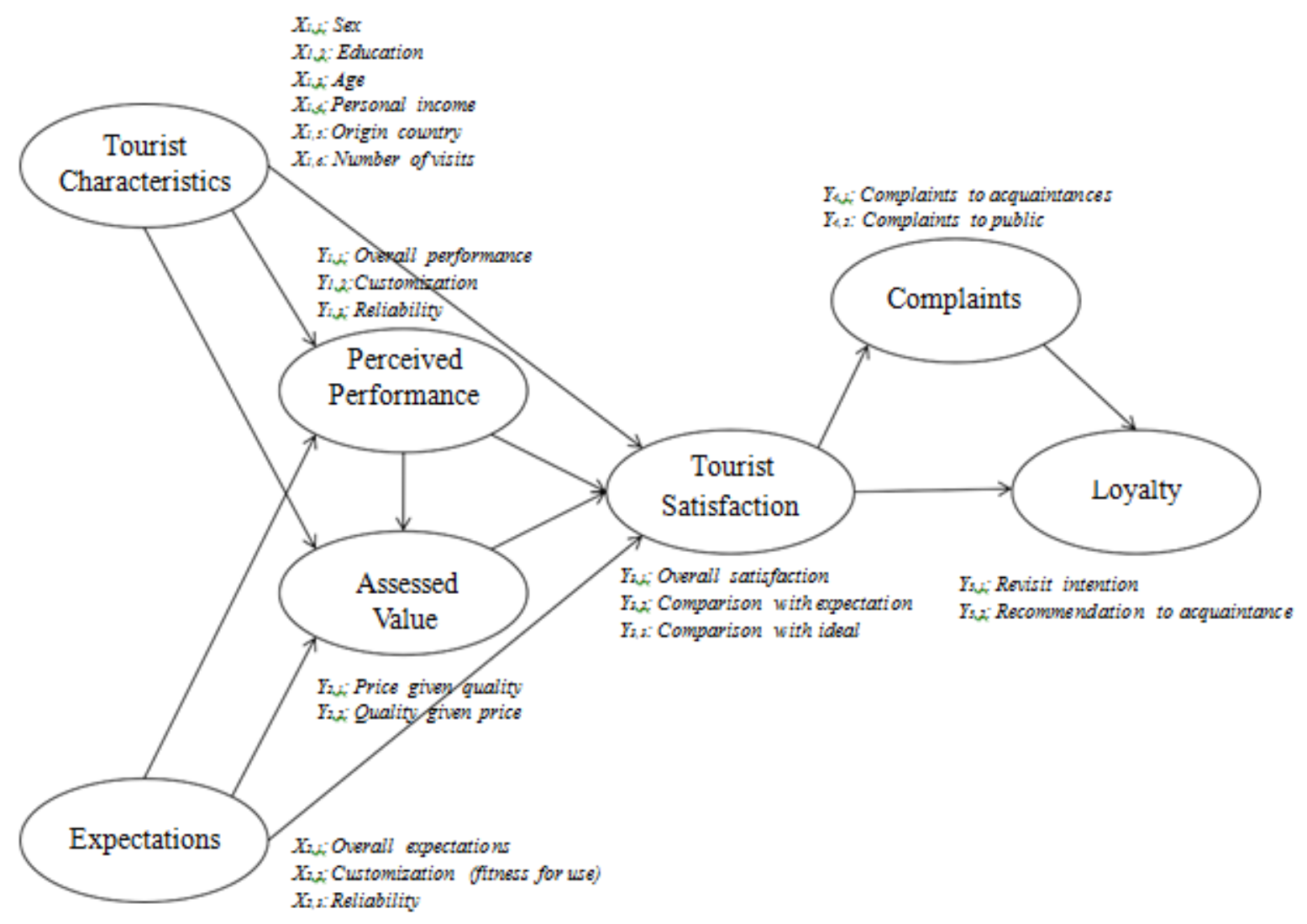

Source: Adopted from Song, Li, Van Der Veen and Chen (2011).

Figure 1 above demonstrates a more conclusive and specified model that is developed as an assessment system for tourists' satisfaction level. Based on Song, Li, van der Veen, and Chen (2011), this model also can be used as a system to tabulate the tourist satisfaction index (TSI). The model summarizes that both tourist characteristics and expectations will affect the perceived performance, assessed value as well as tourist satisfaction. While perceived performance will also affect assessed value by tourists, tourist satisfaction will be affected by four main factors; tourist characteristics, expectations, perceived performance and assessed value. Perceived performance is also known as the perceived value by tourists, which is measure by the overall performance, customization and reliability of a tourist destination.

\section{Literature Review}

Vinh (2013) indicated that motivation research is one of the most essential tools used to gather information regarding tourist opinion of a destination before their visit from the perception of the destination attributes as well as holistic impression made by destination. Dann (1981) defined push factors as the internal drives or the desire to travel such as the need to escape, the need for novelty, or the need for self-esteem, while push factors are the 
attractiveness for travel destinations that motivates tourist to visit tourism site and it is most model has been used (Dann, 1977). For example, study by Yoon and Uysal (2005) regarding tourist travel is mainly driven by the pull and push motivational aspect and those factor really influence tourist and also external forces of the destination attributes of the country. Mohammad and Som (2010) further described that most push factors are intangible or intrinsic desires of the individual travelers, while pull factors are those emerged as a result of the attractiveness of a destination, and thus these factors include tangible resources and traveler perceptions and expectations. Their study regarded the tourist's travel behaviour is driven by internal and external factors. Tourists visit tourism site to fulfill their intrinsic desires, and at the same time, their decisions on where to go are based on destination attributes.

In contemporary tourism studies, perceived value has been emphasized as a significant determinant in tourism researches (Meng, Liang, \& Yang, 2011). Past studies evolved the consumer value concept based on two consumer behavior dimensions: the economic values which associated to perceived prices, and psychological values which actually influence the choice of the product such as emotional aspects (Gallarza\&Saura, 2006). Perceived value is universally defined as the overall assessment of the utility of a product based on the perception on what is received and what is given (Zeithaml, 1988). Most common identified perceived values are the four dimensions: emotional values, social values, and two types of functional values which are price value and performance quality. Further studies on consumer value include quality perceived based on efficiency and excellence.

Many academic and commercial tourism literatures discussed the nature of tourist experience as well as experience of a tourism place. The quality of experience is primarily determined by the intimacies existed between the people at that particular place especially that exists between visitors (Trauer\& Ryan, 2005). Trauer and Ryan (2005) argued that tourism activities are service relationships with emotional attachment through focus on the special interest and enduring involvement level of participants. Involvement includes two: first, an interest with the activity, and second, sharing mutual interests among people in a social world that extends from home to tourist destination.

Overall satisfaction is the extent of overall pleasure or contentment left by tourist, resulting from the ability of the trip experience to fulfill tourist's desires, expectations, and needs in relation to the trip (Chen \& Tsai, 2007). Other studies by Baker and Crompton (2000), Bultena and Klessig (1969), and Dann (1981) defined tourist satisfaction as the connection with motivations, activities, preferences, psychological outcomes, and experience expectations. Based on a study by Yun and Marion Joppe (2011), satisfaction is defined as a post-trip evaluative judgment and affective feeling concerning a travel experience.

\section{Methodology}

\subsection{Data Collection}

The medium of data collection is carried out by using questionnaire in order to measure the satisfaction level of visitors towards homestay as accommodation and tourism spot. The 


\section{Macrothink}

research was carried out at randomly homestay in in Kuching division. The sample is consisted of local and foreign visitors who visited homestay in Kuching during April and May 2015. Sampled respondents were approached and informed about the purpose and objectives of the research. A total of 150 questionnaires were collected. However, 15 observations from overall number have been done for pilot study in purpose to test the feasibility and reliability of the questionnaire which computed using Cronbach's Alpha method and also ANOVA. Hence, the result was significant and the question is usable for next step with target sample population. The questionnaire includes six sections: A) demographic background and visitor's travel behavior variables; B) emotional value; C) experiential value; D) functional value; E) return visit; and F) overall experience based on Hypothesized Sectorial-Level Tourist Satisfaction Index Model. The framework proposed that all the independent variables are Emotional Value, Host-Guest Interaction, Activity, Culture and Knowledge, Establishment, Price and Services, have causal effect relationships towards the dependent variable, Satisfaction Level.

\subsection{Hypothesis}

$\mathrm{SLi}=\mathrm{f}(\mathrm{X} 1, \mathrm{X} 2, \mathrm{X} 3, \mathrm{X} 4, \mathrm{X} 5, \mathrm{X} 6)$

Hypotheses are constructed as assumptions of causal theory between observed variables.

i. X1: Service

H0: Service does not have a positive effect on Satisfaction Level.

HA: Service has a positive effect on Satisfaction Level.

ii. X2: Host-Guest Interaction

H0: Host-Guest Interaction does not have a positive effect on Satisfaction Level.

HA: Host-Guest Interaction has a positive effect on Satisfaction Level.

iii. X3: Price

H0: Price does not have a positive effect on Satisfaction Level.

HA: Price has a positive effect on Satisfaction Level.

iv. X4: Activity, Culture and Knowledge

H0: Activity, Culture and Knowledge does not have a positive effect on Satisfaction Level. HA: Activity, Culture and Knowledge has a positive effect on Satisfaction Level. 
v. X5: Emotional Value

H0: Emotional Value does not have a positive effect on Satisfaction Level.

HA: Emotional Value has a positive effect on Satisfaction Level.

\section{vi. X6: Establishment}

H0: Establishment does not have a positive effect on Satisfaction Level.

HA: Establishment has a positive effect on Satisfaction Level.

\subsection{Reliability and Validity of Data}

Reliability can be thought of as consistency in measurement. In this research, Cronbach Consistency Reliability test was adopted which tested the consistency and reliability of the tourists' satisfaction measurement used in the survey instrument. Accordingly, the reliability of tests on selected attributes is accomplished and therefore, validity tests can be determined. Validity indicates the degree to which an attribute instrument(independent variables) measures the construct (dependent variable) under investigation. Based on Zikmund (2000), content validity refers to the subjective agreement among professionals that a scale logically and accurately reflects what it supposed to measure. Accordingly, the attributes content validity was strengthened through an extensive literature reviews.

\subsection{Factor Analysis}

In this study, exploratory factor analysis (EFA) was adopted to identify the underlying relationships between measured variables. EFA is used to search for structure among a set of variables, or as a data reduction method; whereby the number of factors or components is not specified a prior. The purpose of EFA is to reduce the number of variables, and to detect structure in the relationships between variables, that is to classify variables. Data reduction can be obtained by calculating for each component group items and overall score of composite measure that pertain as much information from the original variables as possible. Therefore, all the variables included in one factor are replaced by a single variable.According to Hair, Anderson, Tatham, and Black (1995), factor analysis is a class of multivariate procedures aiming to identify underlying structure in a data matrix.CFA is the next step after EFA which is used to determine the factor structure of the dataset. To do so, CFA test a priori hypotheses about relations between observed variables and latent variables or also known as factors. According to Brown (2006), this analysis is one of the most reliable analytic tools for developing and refining measurement instruments, assessing construct validity, identifying method effects, and evaluates invariance across groups.EFA may be appropriate for scale development while CFA would be preferred where measurement models have a well-developed underlying theory for hypothesized patterns of loadings (Hurley et al., 1997). 


\subsection{Inferential Statistics}

Inferential statistics were used to test hypotheses, make inferences, and draw the conclusions that can be extended beyond the immediate data themselves. The inferential statistics that this study adapts were described below. The inferential statistics that had been used in this study were ANOVA t-test, F-test and R-square.

\subsection{Multiple Regressions}

To examine the factors that influencing the satisfaction level on homestay, this study adapted the multiple regression analysis, by using the satisfaction level data as a dependent variable. Multiple regression allow the evaluation of the association between a set of independent variables and a dependent variable. Multiple regression also evaluate the relative importance of each independent variable to the change in the dependent variable scores. The regression model is computed as follows:

$\mathrm{SLi}=\alpha+\beta 1 \mathrm{X} 1+\beta 2 \mathrm{X} 2+\beta 3 \mathrm{X} 3+\beta 4 \mathrm{X} 4+\beta 5 \mathrm{X} 5+\beta 6 \mathrm{X} 6+\varepsilon$

Where $\alpha$ and $\beta$ i are parameters to be estimated.

SLi - Satisfaction Level of respondent $\mathrm{i}$

X1 - Services

X2 - Host-Guest Interaction

X3 - Price

X4 - Activity, Culture and Knowledge

X5 - Emotional Value

X6 - Establishment

$\varepsilon \quad-$ Error term

\section{Results and Discussion}

An Explanatory Factor Analysis (EFA) was conducted by utilizing SPSS for a sample of 150 respondents. Factoring Method has extracted the number of components. By using Maximum Likehood method, it would maximizes the differences between factors and provide model fit estimation. This approach is appropriate for EFA and also can proceed to Confirmatory Factor Analysis (CFA) in SPSS and structural modeling. High reliability of the response as can be seen in table 1 . 
Table 1: KMO Statistic and Barlett's Test

$\begin{array}{lll}\text { Kaiser-Meyer-Olkin Measure } & \text { of Sampling Adequacy } & 0.930 \\ & \text { Approx. Chi-Square } & 2865.361 \\ \text { Bartlett's Test of Sphericity } & \text { df } & 276 \\ & \text { Sig. } & 0.000\end{array}$

Table 1 show that KMO Statistic and Barlett's Test is 0.930 and 0.000 respectively. Both results are excellent and significant. Hence, it also shows that these data are reliable. Next is to analyze the factor structure. Factor structure refers to intercorrelation among the variables tested in EFA. The factor structure computed shows that the multiple variables are grouped into six factors. These six factors are extracted based on fixed number of factors because this research aims to attain the proposed number of factors to explain the dependent variable, thus neglecting the eigenvalue. In obtaining a 'clean' factor structure with high loadings, cross-loadings between factors must be eliminated. Besides that, low loadings less than 0.4 are also unacceptable as loadings of 0.4 and lower means that the item explains the factor poorly. Thus, 7 items (service 2, service 3, service 4, service 5, price 4, activity 4, and establishment 4) are eliminated to ensure that there are no cross-loadings and loadings are above 0.4 .

To summarize:

Table 2: Exploratory Factor Analysis

Factor $1 \quad$ Service

Factor $2 \quad$ Host-Guest Interaction

Factor $3 \quad$ Price

Factor 4 Activity, Culture and Knowledge

Factor $5 \quad$ Emotion Value

Factor $6 \quad$ Establishment

The following step is to examine the factor structure of the data set using Confirmatory Factor Analysis (CFA). CFA is use to 'confirm' the factor structure that was extracted in EFA using SPSS software. In CFA, the factor structure needs to meet the criteria of model fit which are analyzed from the computed matrices, modification indices, and standardized residual covariances. So, appropriate alterations are required to take place accordingly to 
obtain the best model that fits these criteria. 20 items are used in the final factor structure while 4 items (service 1, service 10, interaction 4, and price 1) are removed. This is because these items have computed majority standardized residual covariances residual that exceeds 0.4. Following that step, model fit criteria'sis determined to measure the model goodness of fit. Criteria included are Chi-square/df (cmin/df)1, p-value2 of the model, CFI, GFI, AGFI, RMSEA3 and PCLOSE4.To ensure goodness of fit of the model, the metrics are required to meet their acceptable thresholds as listed by $\mathrm{Hu}$ and Bentler (1999). The resulted model fit indicates that chi-square/df of 2.069 is good (less than 3), yet a p-value of zero does not meet the acceptable threshold (more than 0.05). Both CFI and RMSEA are moderately acceptable. However, GFI, AGFI and PCLOSE did not meet their respective acceptable thresholds, indicating that the model is less fit.

Following that, checking for validity and reliability of factors are necessary to demonstrate its adequate validity and reliability to be able to proceed to causal modeltesting. All factors have surpassed the acceptable thresholds of both convergent and discriminant validity values except for Emotional factor. Emotional factor shows discriminant validity issue with its AVE is less than the MSV. The occurrence of discriminant validity issues usually signifies that the variables correlate more with highly with variables outside their parent factor than with the variables within their parent factor. It may also indicated that the latent factor is better explained by some other variables (from a different factor), than its own observed variables. Moreover, other discriminant validity issue detected is the square foot root of the AVE for Emotional is less than one the absolute values of the correlations another factor. The suggested thresholds values are referred from Hair, Black, Babin and Anderson (2010) as shown in the table below:

Table 3: Convergent and Discriminant Validity Values

\begin{tabular}{lll}
\hline Reliability & Convergent Validity & Discriminant Validity \\
\hline $\mathrm{CR}>0.7$ & $\mathrm{AVE}>0.5$ & $\mathrm{MSV}<\mathrm{AVE}$ \\
& $\mathrm{ASV}<\mathrm{AVE}$ \\
& $\begin{array}{l}\text { Square root of AVE greater than } \\
\text { inter-construct correlations }\end{array}$ \\
\hline
\end{tabular}

Next, invariance is tested to validate the factor structure and loadings before creating composite variables for a path analysis. It is resulted that the overall model is invariant between two groups (male and female) which signify that the groups are not different at the model level, yet could be different at the path level. Thus, concluding the confirmatory factor analysis, the proposed model may not be the best fit with the following reasons: 1) fail to meet all thresholds for goodness of fit model, 2) presence of minor discriminant validity issue, and 3) presence of common method bias. Since issuesdetected in CFA are unavoidable and not much fixing can be done due to various factors and reasons, the proposed model will be 
used for regression.

The reliability of the questionnaire is measured using the Cronbach's Alpha. Cronbach's Alpha is acceptable at a value that is greater than 0.5 which indicates that the questionnaire is good. In other word, it means that the questionnaire is easy to understand by respondents. The questionnaire used in this research has a Cronbach's Alpha of 0.958 which is excellent and indicates that the scale used in this research is acceptable, as well as the questionnaire used are easily understood by respondents. The following section discusses the reliability of all the subscales individually to examine the consistency of the item-level errors within a single factor. Cronbach's Alpha is also used to test the reliability of each factor. Cronbach's Alpha is acceptable with value above 0.7 , with each factor to have at least 3 variables although 2 variables is somewhat permissible. Cronbach's Alpha for each factors are acceptable.

Table 4: Reliability Cronbach's Alpha

\begin{tabular}{|c|c|c|c|c|c|}
\hline $\begin{array}{l}\text { Reliability } \\
\text { Services: } \\
\text { Cronbach's } \\
\text { Alpha = } \\
0.901\end{array}$ & $\begin{array}{l}\text { Reliability } \\
\text { Host-Guest } \\
\text { Interaction: } \\
\text { Cronbach's } \\
\text { Alpha = } \\
0.902\end{array}$ & $\begin{array}{l}\text { Reliability } \\
\text { Price: } \\
\text { Cronbach's } \\
\text { Alpha = } \\
0.850\end{array}$ & $\begin{array}{l}\text { Reliability } \\
\text { Activity, } \\
\text { Culture and } \\
\text { Knowledge: } \\
\text { Cronbach's } \\
\text { Alpha }=0.878\end{array}$ & $\begin{array}{l}\text { Reliability } \\
\text { Emotional } \\
\text { Value: } \\
\text { Cronbach's } \\
\text { Alpha = } \\
0.842\end{array}$ & $\begin{array}{l}\text { Reliability } \\
\text { Establishment: } \\
\text { Cronbach's } \\
\text { Alpha }=0.884\end{array}$ \\
\hline Service 6 & Interaction 1 & Price 2 & Activity 1 & Emotion 1 & Establishment 1 \\
\hline Service 7 & Interaction 2 & Price 3 & Activity 2 & Emotion 2 & Establishment 2 \\
\hline Service 8 & Interaction 3 & & Activity 3 & Emotion 3 & Establishment 3 \\
\hline Service 9 & Interaction 5 & & & Emotion 4 & \\
\hline
\end{tabular}

After that, for multiple regression, intercorrelation between all variables has to be checked and If any of the correlations are too high (say above 0.9), it is necessary to remove one of the variables from the analysis as the two variables seem to be measuring the same thing. It is found that there are several variables conveyed relatively high correlations but are still acceptable to be used in this study as they are still below 0.9. Among the highest are correlations between 'emotional value' and 'establishment' (0.815), 'service' and 'establishment' (0.839), 'Activity, Culture and Knowledge' and 'emotional value' (0.82), 'host-guest interaction' and 'emotional value' (0.848), and, 'host-guest interaction' and 'establishment' (0.823). Following that, the variables are regressed. The regression model constructed by SPSS is shown as below. 


$$
\begin{aligned}
& \mathrm{SLi}=-0.068+\quad 0.195 \mathrm{X} 1+\quad 0.220 \mathrm{X} 2+\quad 0.039 \mathrm{X} 3+0.344 \mathrm{X} 4+\quad 0.483 \times 5-0.95 \times 6+\varepsilon
\end{aligned}
$$

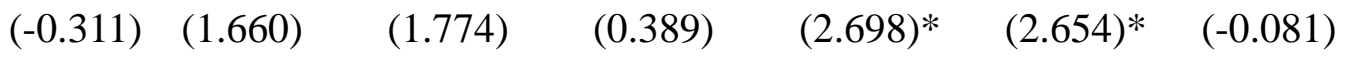

R-square $=0.698$, F-test $=55.017(0.000)$ and Durbin-Watson $=2.041$

The R-square for the constructed regression model is 0.698 , indicating that 69.8 percent of the explanatory power of the independent variables can explain the dependent variable. 69.8 percent shows that the independent variables are moderately good in explaining the Satisfaction Level. The remaining percentages (30.2 percent) are explained by other rejected factors. The value of F-test is 55.017. The probability value for F-test (0.000) is below alpha $(\alpha=0.05)$ which signifies that there are enough statistical evidence to reject the null hypothesis. This means that the model is significant at 95 percent confidence level, whereby all coefficient slopes are statistically significant simultaneously and the whole model is fit. The Durbin-Watson value is 2.041 , which is above the limit of 1.5 . The value of slightly greater than 2 indicates that there is no autocorrelation in the model.

Table 5: SPSS Regression Output

\begin{tabular}{|c|c|c|c|c|c|}
\hline Model & Unstandardized & Coefficients & $\begin{array}{l}\text { Standardized } \\
\text { Coefficients }\end{array}$ & $\mathrm{t}$ & Sig. \\
\hline & $\mathrm{B}$ & Std. Error & Beta & & \\
\hline (Constant) & -0.068 & 0.217 & & -0.311 & 0.756 \\
\hline Service & 0.195 & 0.117 & 0.169 & 1.660 & 0.099 \\
\hline $\begin{array}{l}\text { Host-Guest } \\
\text { Interaction }\end{array}$ & 0.220 & 0.126 & 0.186 & 1.744 & 0.083 \\
\hline Price & 0.039 & 0.100 & 0.033 & 0.389 & 0.698 \\
\hline $\begin{array}{l}\text { Activity, } \\
\text { Culture and } \\
\text { Knowledge }\end{array}$ & 0.344 & 0.128 & 0.287 & 2.698 & 0.008 \\
\hline $\begin{array}{l}\text { Emotional } \\
\text { Value }\end{array}$ & 0.483 & 0.182 & 0.313 & 2.654 & 0.009 \\
\hline Establishment & -0.095 & 0.149 & -0.081 & -0.641 & 0.523 \\
\hline
\end{tabular}

a. Dependent Variable: Satisfaction Level 
Based on the table above, Service, Host-Guest Interaction, Price, Activity, Culture and Knowledge, and Emotional Value show positive impacts Satisfaction Level, while Establishment shows negative impact on Satisfaction Level. Following that, the unstandardized Beta coefficients show the degree of impact each independent variables have on Satisfaction Level. Further justification implies that when Service goes up by 1, Satisfaction Level goes up by 0.195 , Host-Guest interaction increases by 1 affect the Satisfaction level to increase by 0.220 , Price is increase by 1 causes 0.039 slight increase in Satisfaction Level, while Activity, Culture and Knowledge increase by 1 causes Satisfaction Level to increase by 0.344. It is shown that Emotional Value has the most impact on Satisfaction Level, where when Emotional Value goes up by 1, Satisfaction Level will goes up by 0.483 . On the other hand, when Establishment is increase by 1, Satisfaction Level decrease slightly by 0.095 .

The probability value ( $p$-value) of ANOVA t-test for each variable must be lower than alpha $(\alpha=0.05)$ to be significant. Activity, Culture and Knowledge, and Emotional Value variables have p-value less than alpha, indicating that they are significant. However, other variables (Service, Host-Guest Interaction, Price, and Establishment) computed p-values greater than alpha, indicating that they are not significant. When a significant test results in a high p-value, it means that the data provides little or no evidence of that the null hypothesis is false. Yet, high probability value is not evidence that the null hypothesis is true. In this case, the null hypothesis is independent variable does not adequately explain the dependent variable. Thus, independent variables with high p-value are concluded of having problem to distinguish a null effect from a very small effect. The relationships between these variables and Satisfaction Level are not entirely insignificant can be retained.

\section{Conclusion}

This research assesses the significant attributes that will affect satisfaction level of homestay experience. The tested attributes have shown both positive and negative effect towards satisfaction level. This study has included different dimensions of perceived valued which are explained by emotional value, experiential value, and functional value.In the discussion section, it has shown that all independent variables affect the Satisfaction Level in a positive manner, except Establishment which computed negative coefficient. This means that Establishment affects Satisfaction Level in a negative manner.Nonetheless, other independent variables have computed positive coefficients, indicating that there are positive relationships between the independent variables and Satisfaction Level. Thus, it can be concluded that the null hypothesis for Establishment are not being rejected, indicating that Establishment does not have a positive effect on Satisfaction Level. This finding can be supported as included in the literature reviews, as the measures might take into account extraneous variables associated with factors outside the control of the service provider and cause a less than perfect correlation between Establishment and Satisfaction Level (Baker \& Crompton, 2000).

Homestay proprietors, managers and marketers recognize of the significance of values in driving visitors' motivations to a tourist destination, in this case, homestay tourism.Pertaining to this, they need to understand the dimensions that contribute to visitors to meet the demands 
of increasingly value-oriented industry. Promoting unique products and services such as conservative homestay concept as a tourist destination constitutes an important task for tourism authorities and their ability to innovate, improve and creatively market tourist experiences to determine their continued success. This study can act as an evaluation of homestay performance that objectively informs tourism authorities and related stakeholders about the performance of the homestays in Kuching Division generally as a whole. The evaluations of this study is able to capture the cause and effect relationship associated with visitors' satisfaction level and identified the relationships between visitors' perceived values and homestay's overall performance based on their overall experience. Moreover, based on the discussions, government and authorities play very important role as one of the greatest supporter to boost the homestay tourism to where it intends to grow. They should consider further step that would benefit operators, villagers as well as guests while promoting the industry to a wider range.

\section{Reference}

Abd Aziz, P., Md Tap, A. O., \& Mahmud, M. (2013). Computer-Supported Cooperative Work in Malaysian Homestay Industry. Information and Communication Technology for the Muslim World (ICT4M), 2013 5th International Conference, (pp. 1-5).

Baker, D. A., \& Crompton, J. L. (2000). Quality, satisfaction and behavioral intentions. Annals of Tourism Research, 27(3), 785-804.

Bhuiyan, M. A., Siwar, C., Ismail, S. M., \& Islam, R. (2011). The Role of Homestay for Ecotourism Development in East Coast Economic Region. American Journal of Applied Sciences, 8(6), 540-546.

Brown, T. A. (2006). Confirmatory Factor Analysis for Applied Research. Confirmatory Factor Analysis for Applied Research, xiii.

Bultena, G. L. and L. L. Klessig. (1969). Satisfaction in Camping: A Conceptualization and Guide to Social Research. Journal of Leisure Research, 1(4), 348-354.

Chen, C. F., \& Tsai, D. (2007). How Destination Image and Evaluative Factors affect Behavioral Intentions? Tourism management, 28(4), 1115-1122.

Dann, G. M. (1981). Tourist Motivation an Appraisal. Annals of Tourism Research, 8(2), 187-219.

Daud, M. M. (2012). The Ecotourism Development in Malaysia. In T. Hundloe (Ed.), Linking Green Productivity to Ecotourism: Experiences in the Asia Pacific Region. In Tokyo: Asian Productivity Organization (APO).

Gallarza, M. G., \& Saura, I. G. (2006). Value dimensions, Perceived value, Satisfaction and Loyalty: An Investigation of University Students' Travel Behaviour. Tourism Management, 27(3), 437-452. 


\section{I Macrothink}

Journal of Public Administration and Governance ISSN 2161-7104 2017, Vol. 7, No. 1

Hair, J., Black, W., Babin, B., \& Anderson, R. (2010). Multivariate Data Analysis (7th Edition ed.). Upper Saddle River, NJ, USA: Prentice-Hall Inc.

Hurley, A. E., Scandura, T. A., Schriesheim, C. A., Brannick, M. T., Seers, A., and Vandenberg, R. J. (1997). Exploratory and Confirmatory Factor Analysis: Guidelines, Issues, and Alternatives. Journal of Organizational Behavior, 18(6), 667-683.

Kayat, K. (2009). Community Based Tourism in Developing Countries. In Proceedings from: The International Seminar on Community Based Tourism. UiTM, Malaysia.

Lama, M. (2013). Community Homestay Programmes as a form of Sustainable Tourism Development in Nepal.

Lim, A. (2012, November 10). Retrieved September 17, 2014, from http://www.theborneopost.com/2013/11/10/boosting-sarawaks-tourism-industry-in-2014/

Meng, S.-M., Liang, G.-S., \& Yang, S.-H. (2011). The Relationships of Cruise Image, Perceived Value, Satisfaction, and post-purchase Behavioral intention on Taiwanese Tourists. African Journal of Business Management, 5(1), 19-29.

Mohammad, B. A., \& Som, A. P. (2010). An analysis of Push and Pull Travel Motivations of Foreign Tourists to Jordan. International Journal of Business and Management, 5(12), 41-50.

Pusiran, A. K., \& Xiao, H. (2013). Challenges and Community Development: A Case Study of Homestay in Malaysia. Asian Social Science, 9(5), 1.

Razalli, M. R. (2008). The Consequences of Service Operations Practice and Service Responsiveness on Hotel Performance : Examining Hotels in Malaysia.

Song, H., Li, G., van der Veen, R., \& Chen, J. L. (2011). Assessing Mainland Chinese Tourists' Satisfaction with Hong Kong using Tourist Satisfaction Index. International Journal of Tourism Research, 13(1), 82-96.

Trauer, B., \& Ryan, C. (2005). Destination image, romance and place experience-an application of intimacy theory in tourism. Tourism management, 26(4), 481-49.

Vinh, N. Q. (2013). Destination Culture and its influence on Tourist Motivation and Tourist Satisfaction of Homestay Visit. Journal of the Faculty of Economics and Administrative Sciences, 3(2), 199-222.

Yoon, Y., \& Uysal, M. (2005). An Examination of the effects of Motivation and Satisfaction on Destination Loyalty: A structural model. Tourism Management, 26(1), 45-56.

Yun, D., \& Joppe, M. (2011). Chinese Perceptions of Seven Long-Haul Holiday Destinations: Focusing on Activities, Knowledge, and Interest. Journal of China Tourism Research, 7(4), 459-489.

Zeithaml, V. A. (1988). Consumer Perceptions of price, quality, and value: a means-end model and synthesis of evidence. The Journal of Marketing, 2-22.

Zikmund, W. (2000). Business Research Methods. 


\section{Macrothink}

\section{Copyright Disclaimer}

Copyright for this article is retained by the author(s), with first publication rights granted to the journal.

This is an open-access article distributed under the terms and conditions of the Creative Commons Attribution license (http://creativecommons.org/licenses/by/3.0/). 